\title{
Derivation of a Design Solution for the Conservation of a Historical Payab in the Redevelopment of Doloeei, Gonabad
}

\author{
Rahman Tafahomi \\ Architecture Department, School of Architecture and Built Environment, College of Science and Technology, University of Rwanda, Kigali, \\ Rwanda \\ Email: rtafahomi@ur.ac.rw \\ Reihaneh Nadi \\ Architecture Department, School of Architecture and Built Environment, College of Science and Technology, University of Rwanda, Kigali, \\ Rwanda
}

\begin{abstract}
This paper aims to demonstrate the conservation process of historic underground water access or Payab by proposing a multistage decision-making design in Gonabad city, northeast part of Iran. The Payab was in the center axis of a street in the proposed development of a new road which appeared to be against the new construction. The challenge was to develop the new road in the central axis without disturbing much the historic structure in the location. Hence, a request was made to keep both the new road and the historic Payab structure with a design solution. In order to tackle the design solution requested, a qualitative methodology was designed by way of site surveys, site documentation, graphical analysis and interviews. The findings of the research demonstrated contradicting opinions among the governors-laypeople, youngers-elders and males and females about the historic structure. Based on the findings, it was proposed that a protective shield, which aimed to conserve the historic structure under the weight of the new road is required, with a new entrance to be provided through an adjacent sidewalk to achieve consensus among those of diverse ideas. As a conclusion, conservation projects as demonstrated in this paper, like any other conservation projects elsewhere are faced with budget limitation, poor planning and the support it needed. As the historic structure has been part of the local built environment, the integration with other architectural elements in the context is of paramount importance to support the sustainability of the local built environment.
\end{abstract}

\author{
Article History \\ Received : 11 April 2019 \\ Received in revised form : 03 December 2019 \\ Accepted : 15 December 2019 \\ Published Online : 31 December 2019
}

\section{Keywords:}

Conservation; Participatory Design; Heritage Structure; Contextual Approach; Protective Shield

\section{Corresponding Author's Contact:}

rtafahomi@ur.ac.rw

DOI: $10.11113 /$ ijbes.v7.n1.407

(C) 2020 Penerbit UTM Press. All rights reserved

\section{Introduction}

Conservation, preservation, and rehabilitation of heritage areas have been multidisciplinary, multidimensional, and interdisciplinary projects and somehow tough task for designers to plan in the developing countries. This kind of project divides developers, users, politicians, experts, people and academicians with different expectations, experiences and believes. In this dialectic of time and location, budget and value, tradition and modern, to be or not to be the historic elements, the new generation of buildings, urban textures, and urban forms thus regenerate.

Studies showed that the historic sites, buildings, and elements have been faced with problems, challenges, and threats from both natural hazards and manmade interventions in the whole history. The natural hazards affected based on the low level of maintenance, budgeting, and financing, additionally, manmade based on the unclear policies, strategies, and implementing tactics (Brimblecombe \& Grossi, 2014). Despite publication series of guidelines and design toolkits by UNESCO, and heritage 
organization in all counties, it seems still needs to specific study, research, and investigation for localizing the culture, knowledge, and approach of conservation.

Iran as a country with both long and wide background of history has been faced with conservation projects with various aspects. Some conservation projects in Esfehan, Kashan, and Yazd were implemented, for other cities and places some plans were provided such Gonabad, Syraph, and Qazvin (ICHHTO, 2016), and some of the site, buildings, and elements still are needed to a conservation project. However, this process always has been confronted with prioritising, financing, and budgeting as more challenging aspects of conservation in the country.

\section{Problem Statement}

Gonabad city is a historic city with a long background in the northeast part of Iran. The historic part of the city was documented, and the plan was approved (Tafahomi, 2010). The historic structure of the Payab (under-ground-water-access) was not included in the documentation project due to the budgeting and timing. In addition, this area of the country did not document in detail, and information was limited to some reports and books (Tabandeh, 1969; Zamani, 1994) with a large scale of the study. So, in those references just could be observed some general statistical data about population, political circumstances, and geographical aspect in the regional scale. Therefore, in the architectural scale, the resources have been so limited.

The Payab is located in the middle part of the Daloei in the suburb of Gonabad city. This historic structure has functioned in adapting with the contextual and the cultural aspects of the daily life to access to the water in the desert wasteland due to the significance function the Qanat (underground water system supply) to support horticulture, agriculture, and settlement in the area. The Payab was the access point to the traditional water supply system for everyone particularly for homemakers when it passed the inhabitant areas; however, males consumed the water in the surrounding farms for cultivation and horticultural activities. Nevertheless, with the new water supply system in the city, the functionality of the historic structure decreased, and it no longer play the same role as it was in the past. However, females preferred to use this structure as a behavioral sitting (Gehl, 2007). Surprisingly, the new proposed road was projected to pass through the heritage structure in the central part of the area, without paying any attention to the historic background, functionality, and acceptability of the historic structure for both government and governance (Harris \& Dines, 1998). Importantly, the local government did not accept to revise on the direction, form, and sections of the new road, due to the approved plan in the bureaucratic process. However, other precedents addressed designing and engineering solutions for those historic elements as the central point in the road with structure of square, roundabout, and open spaces (French, 1983; Krier, 1991; Antoniou, 2002) to conserve the historic or heritage element in the location. Nevertheless, the transport engineers did not plan such kind of innovation to respect to the historic structure. Hence, the clear request was to keep both the new road and the historic structure with a design solution.

\section{Theoretical Framework}

Cities have produced urban textures, fabrics, and forms based on the environment, culture, and history in the development process (Benevolo, 1980; Altman \& Chemers, 1984; Radoslav, et al., 2013; Shin, et al., 2015). Especially, the historic cities have been included varieties of architectural elements from different times and eras those could introduce as the symbols of transition process of the urban evolution (Morris, 1994; Tafahomi, 2007). In this process, some of those architectural historic elements replaced with new elements in the process of renovation, reconstruction, and redevelopment (Radoslav, et al., 2013). However, the influence of the replacement of those historic elements has affected the memories of laypeople with the new image of the city that adaptation with the new forms has not been easy for users although users may not recognize this process in a short time (Llopis, et al., 2015).

Every historic city has encompassed the specific historic elements those recognized as the heritage and characteristic elements in the city. Those characteristic elements have included both physical and nonphysical elements as a part of the character of the city. For this reason, in the more documents in the urban design, urban planning, and landscape design have been emphasized the keeping those characteristic elements (American Planning Association, 2006; Llewelyn-Davies, 2000) in term of the identity of place (Relph, 2007). However, this has not been easy action. For example, other researches demonstrated that planning and design for heritage areas were frustrated with constraints of municipality budgeting for this kind of projects (Raymond, 1984; Means, 2004).

Nevertheless, the heritage, conservation, and preservation have been a critical issue in all countries and the motto of the EU as "Discovering the Past, Shaping the Future" (Heritage, 2005) could demonstrate how the conservation has been significant. However, activities in the conservation areas have been somehow separated and did not document well in the world. For example, in the study of Brimblecombe \& Grossi, they emphasized that if there were some; they did not convert into policies, strategies, and implementation tactics (Brimblecombe \& Grossi, 2014) in both natural hazards such as earthquakes, flood, and runoff, and manmade intervention such as poor maintenance, vandalism, and demolishing. However, remarkably, in those available reports on the precedents earthquakes in the area did not observe any cases about damaging or destroying the underground structures.

The conservation in the country mostly has tended to the protection than conservation due to the background, however, some projects in the Yazd, Kashan, and Esfehan have been oriented to the rehabilitation for some touristic proposes than historic (Tavasoli, 2000). In this alignment, studies released using of traditional materials and technology in the conservation, rehabilitation, and vitalization project have been in the same orientation with the resiliency of project in the context than an integration of new materials (Amicoa \& Curràb, 2014). In detail, some researches, studies, and rehabilitation projects on the historic cities emphasised this approach in the country as well (ICHHTO, 2016). 
In addition, some precedents suggested applying the participatory design for more effectiveness results (Manzini \& Rizzo, 2011; Hussain, et al., 2012; Iversen \& Dindler, 2014). This process has tended to collaboration between designers, users, and stakeholders (Hussain, et al., 2012), in the whole process of design. Indeed, in this process, researchers have recommended shifting from the final product to the social production approaches (Manzini \& Rizzo, 2011; Iversen \& Dindler, 2014). In addition, some the researches have reformulated the participatory design into co-design and co-creativity phrases (Sanders \& Stappers, 2008). However, application of this approaches has been faced with difficulties in particular countries (Raymond, 1984), and sometimes participation of people resulted in chaos (Hillier, 2002). Nevertheless, this process has facilitated the decision making (Dyson, 2004) but have not been any guarantee of decision taking.

\section{Methodology}

The methodology of this research was designed with the qualitative method (Dandekar, 1988; Groat \& Wang, 2002) with approach of the research through design (Faryling, 1993) and application of observation (Silverman, 2004; Neuman, 2006), interviewing (Neuman, 2006), photography (Llopis, et al., 2015; Tafahomi \& Nadi, 2016), and graphical analysis (Dandekar, 1988; Laseau, 2000). The data was combined through site survey, precedents analysis, laypeople perceptions, and overlaying of analytical data. For this process, first, the photogrammetric map updated with physical elements in the site such as the structure of the Payab and the new road in the micro-scale (Moughtin, et al., 1999; Miller, et al., 2004). Then through photography (American Planning Association, 2006) the position, condition, situation and visual quality (Bell, 2004; Bell, 2008) of the historic structure documented (Tafahomi, 2009; Tafahomi \& Nadi, 2016). Then, the physical condition of the Payab measured and documented with metric survey (Groat \& Wang, 2002). The interview was included both governmental bodies and laypeople including four groups of male, female, youth, and elder people (Silverman, 2010). Through of those discussions with respondents were discovered the sense of place (Dondis, 1973; Pallasmaa, 2005), perception (Altman \& Chemers, 1984) of the structure in the wider landscape (Deming \& Swaffield, 2011).

\subsection{Case of Study}

The Payab in Daloeei located in the Historic part of Gonabad city in northeastern part of Iran. The history of the city referred to the around 200 B.C however, all historic aspects were destroyed in three intensive earthquakes. Just those ancient Qanats could refer to the old historical aspects of inhabitants in the area. Therefore, all architectural heritage elements belong in 1100 A.D and after that (Ghirshman, 1954; Tafahomi, 2010). The Payab located in the one of the pre-urban areas with the direct connection to the bypass of the city. The new proposed road as redevelopment project scratched the face of the historic fabric through passing in the central part of the area without concerning the historic structure. The historic structure has been the most important heritage element in the area, however; there was not any archaeological investigation or research to discover other sites due to the limited budget for historical research. The project requested based on the proposal of laypeople to warn the local manager for renovation, rehabilitation, or conservation.

\subsection{Site Survey, Data Collection and Analysis}

The analysis combined from several techniques, data, and processes. In the survey, physical size and the form of the Payab were estimated through observation, measurement, and recording. The observation included two groups of the data including first the physical elements particularly applied materials, scale, and technology in the structures, second behavioral patterns of users. This observation was not limited to the historic structure; however, other similar structures in the surrounding areas were surveyed.

The site survey took place on-site for two weeks with visits arranged either in the morning or in the afternoon. The Payab was located in the courtyard of an old mosque that with the road expansion, it automatically shifted in the middle of the new road and surprisingly the consulting company never took into account the heritage structure in the designing of the new road. The structure was damaged by the heavy road constructions machines, the entrance destroyed, and the accessibility was so difficult. The roof skylight-visors filled with construction materials based on the soil operations on the road and the inside of the structure was so dirty, dark and unsafe. The entrance was full of wastes and rubbishes.

The size of the structure was $4 \mathrm{~m}$ height, $4.5 \mathrm{~m}$ width, and $7 \mathrm{~m}$ length. The structure was constructed with bricks and carves form of arch as the roof structure. The entrance was not part of the foundation of the structure, but it was an additional element. According to the form, shape, and material of the bricks in the historic structure and the stairs of the entrance, it was clear that the entrance and steps reconstructed. The Payab included one entrance, two retables for candles lighting and shelf, two filled skylight in the roof, some traces of four broken stone seats, one channel of water, and two small ponds in the water streams.

Materials of the structure were bricks but some part particularly the roof part covered with stucco and lime mortar several layers due to adaptation with water wetness and moistness. The ground was covered with varieties of materials and mortars, so the recognition of the original materials without an excavation and archaeological operation was impossible. However, the stream of the water channel was paved with some red stones blocks those have been available in the surrounding mountains.

Temperature surprisingly was so calm and comfortable in the structure. The temperature and humanity measured with the electronic thermometer four times. It was from 25 to 28 centigrade and humidity was around 80 that this condition was understandable due to the filled skylights in the structure that it has limited the ventilation and circulation of the air through the hole. In the discussion with local people, they expressed that the atmosphere of the Payab has been more comfortable than outside in both hot summer and cold winter. Certainly, this comfortability specification has been one of reason to choose this position as one of the behavioral sittings by females as a hangout. In addition, the song of the water all the time like a music background could help them for more relaxation.

Observations were simultaneously made for two weeks with visits arranged either in the morning or in the afternoon. The purpose was to visit the historic structure, other adjacent structures, 
behavioral patterns as well as activities. No activities at all in the surrounding of the historic structure and the new redevelopment construction as the central road totally changed the lifestyle in the area as the photos in rows $1-5$ in table 1 . The area was similar to a construction site, so no female activities observed, but in the other precedents could be observed how female using of the Payab as a behavioral sitting as the row 6 in table 1 .

For example, in other precedents in the area, there were some short and rough stones as benches for sitting and using water and more light from the entrance. Inside of the structure, the pattern of activities was based on a few numbers of users in the same time due to the small size of the room. Therefore, maximum ten users were able to attend in the structure at the same time based on the design, but current situation just allowed maximum five users. The attendance of users has not been randomly but based on the relativities, neighbours, and friendship arrange the group of users due to the discussion with users and elders. According to the user's explanations', enter to the structure was always free for the females but for any male just allowed with permission of female users as a traditional value.

The physical activities were included washing large-scale materials such as carpet, blankets, and dresses, or pots. The washing was not just as compulsory activities but a conversation, chatting, and social interactions were more important in the location. Some of users just participated for chatting not any physical activities particularly elders, and sometime smoking of cigarets in the tropical climate without public demonstration.

In the visiting of the surrounding area, in some precedents, some kinds of the material recognized as available, affordable, and durable materials. The surrounding area included some hills and mountains those included red stones as the one of the traditional materials in the area. In addition, the jujube trees have been one of common medical and fruit trees in the area that the wood applied for column, charcoal, and carpentry with strong and dark brown colours. In addition, it was produced fired bricks in the area; however, the price was more expensive than imported one.

Table 1 Survey Results of the Historic Structure

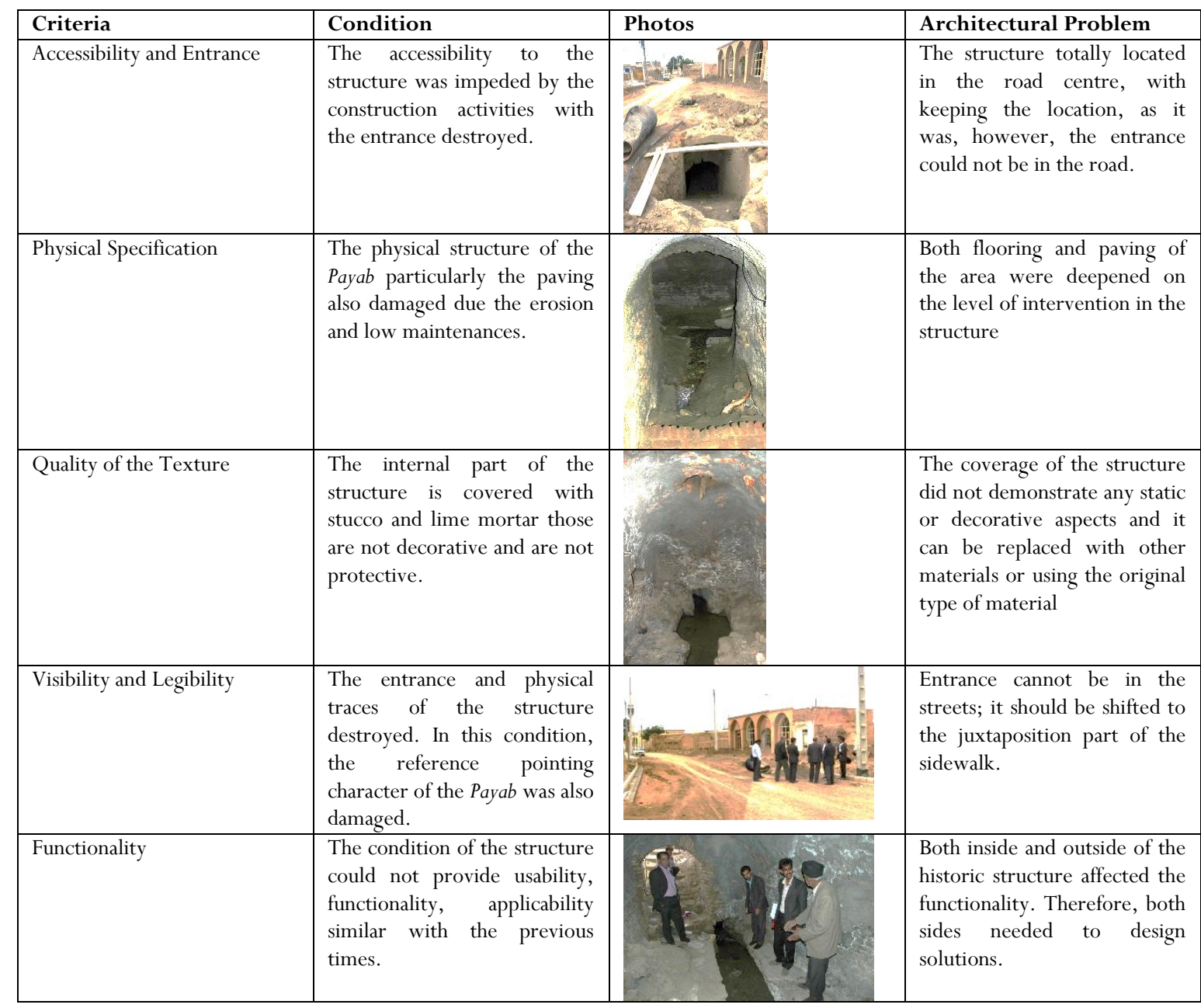




\begin{tabular}{|l|l|l|l|}
\hline Activities & $\begin{array}{l}\text { Those damaged seats, } \\
\text { entrance, and stairs could not } \\
\text { attract the original users. }\end{array}$ & $\begin{array}{l}\text { The interior space should } \\
\text { design to adapt with need, } \\
\text { desire, and expectation. }\end{array}$ \\
\hline
\end{tabular}

Table 2 Summary of the Key Ideas by the Respondents

\begin{tabular}{|c|c|c|}
\hline Respondents & Observation & Requests \\
\hline Local manager & $\begin{array}{l}\text { - Low quality of space } \\
\text { - Low number of tourists } \\
\text { - Stopping the construction project }\end{array}$ & $\begin{array}{l}\text { - Renovation of the structure } \\
\text { - Upgrade it as a tourist attraction }\end{array}$ \\
\hline Governor & $\begin{array}{l}\text { - Construction of the road should stopped } \\
\text { - No satisfaction among laypeople } \\
\text { - Budget problem }\end{array}$ & $\begin{array}{l}\text { - Keeping the historic element } \\
\text { - Rehabilitation of the area } \\
\text { - Creation tourist attractions } \\
\text { - Conserve the historic structure } \\
\text { - Renovate }\end{array}$ \\
\hline Councilors & $\begin{array}{l}\text { - The construction takes a long time } \\
\text { - No policy for renovation or conservation } \\
\text { - The damage rendered the structure useless }\end{array}$ & $\begin{array}{l}\text { - Renovate the structure } \\
\text { - Build the road } \\
\text { - Make prompt decision }\end{array}$ \\
\hline Heritage officer & $\begin{array}{l}\text { - Unregistered heritage element } \\
\text { - Limitation of budget for more research } \\
\text { - Claim of people about the road } \\
\text { - No support from the central government for conservation of } \\
\text { the area }\end{array}$ & $\begin{array}{l}\text { - Conservation of the structure without any } \\
\text { renovation } \\
\text { - Open the road } \\
\text { - Guarantee no damage to the structure } \\
\text { - Pass the road on the structure }\end{array}$ \\
\hline Laypeople Males & $\begin{array}{l}\text { - The Payab has been a female area } \\
\text { - It is no longer important } \\
\text { - }\end{array}$ & $\begin{array}{l}\text { - It can be removed from the new road } \\
\text { - Other area can be constructed new one }\end{array}$ \\
\hline Laypeople females & $\begin{array}{l}\text { - Useful area for washing } \\
\text { - Females like the room } \\
\text {-It can work for gathering } \\
\text { - Good place for resting }\end{array}$ & $\begin{array}{l}\text {-Renovation the structure } \\
\text { - Reconstruct the inside } \\
\text {-Add facilities such as lights, seats, and power } \\
\text { - Apply high quality of materials in renovation }\end{array}$ \\
\hline Laypeople Elders & $\begin{array}{l}\text { - It is the identity of the area } \\
\text { - It is an important part of history } \\
\text { - It is part of the culture } \\
\text { - It is full of memory for the next generation }\end{array}$ & $\begin{array}{l}\text { - Keep the structure as it is } \\
\text { - Renovation of the structure } \\
\text { - Find engineering solution of the road } \\
\text { - Make it visible for tourists }\end{array}$ \\
\hline Laypeople youth & $\begin{array}{l}\text { - It is an old structure which is no longer useful } \\
\text { - It is so dirty and unsafe for females } \\
\text { - It is not healthy area to use the water } \\
\text { - Budget should allocated for sport than renovation of a useless } \\
\text { building } \\
\text { - It is not a symbol of the culture }\end{array}$ & $\begin{array}{l}\text { - Demolish the structure } \\
\text { - Open the road } \\
\text { - Renovate the area } \\
\text { - Built recreational activities than historic }\end{array}$ \\
\hline
\end{tabular}

The interviews had included two major groups of the respondents including the first part as the governmental bodies like the local urban manager, member of the council, Heritage supervisor officer, and politicians, and the other side laypeople included male, female, youth, and elder. The interviews took place in three different location including governor office, village council, and heritage center. Majority part of the governmental bodies believed that the heritage structure should conserve at it was without any changes, renovation, decoration, and integration, under influences of the heritage officer. However, local manager believed that the structure should renovate as a touristic asset to facilitate circulation of income for the local people.
Interview with the local people was more diverted from a unique central point of view. The interview took the position in the mosque, tomb, library, and gardens. For the elder people particularly male, the structure should keep as a heritage asset and value for the next generation to deliver the traditions and lifestyle without any intervention. However, generally they believed that the Payab structure has been a feminine realm than masculine, so, opinions of the females should be more important than male. For the females, the structure still was included functions to serve the female needs such as access to water, safe, and chatting area, however, it needed more renovation, decoration, and facilities such as light, ventilation, and sitting areas. Nevertheless, for the younger inhabitants, the time of the historic structure expired and no longer, this structure can work with the new system of the 
water supply and sanitation; but the new road was more important than the old structure in the area. Therefore, they recommended filling the historic structure with the soil and construction wastes as the basement of the new road. All the results of the interviews summarized in table 2 .

These kinds of contradictions were predicated on the circumstance of the research in the traditional context. So, for overcoming the problem, the several discussions with both governmental and laypeople arranged and finally the opinion of the heritage officer and female respondents concluded as the benchmark of the project for designing process.

\section{Findings and Derivation of a Design Solution}

Despite the contradiction among respondents, the results identified that major tendency was to conserve the structure with rehabilitation approach, for both user and tourists to achieve the new road construction. However, this tendency was higher among elder, female and heritage office, selecting a conservationrehabilitation approach created a consensus between government and governance in the designing process to achieve all expectations of users. Additionally, the results demonstrated that new generations were not proud of the historic structure as the symbol of the heritage and tradition and they preferred renovation and modernity. Therefore, it could be argued that the function of the structure as a public service decreased and the current role of the structure was not clear in the modern city. In this regard, all strategies of design were oriented with an integrated conservation and rehabilitation approach for solving the problem.

To achieve the task of protection of the heritage structure in the location with the ability to stand under weights of the road and those heavy machines, the solution was to conceptualize a protective shield in the surrounding like a box to keep the structure in the inside safely. The concept was to form a spatial envelopment to put the historic structure inside for conserving also to open the new road. Simultaneously, the box also should be included openness to be accessed from the outside to the inside. Therefore, this idea developed into the idea of an underground bridge in the upper side of the historic structure to protect it from upper sides and convert the weights of the roads and transports into the ground. Simultaneously, the issue of the earthquake has been crucial matter particularly with the vacation of surrounding area of the structure; the historic resistance of the historic structure dramatically decreases. To solve this issue, in discussion with the civil engineer teams, it was decided to unify the foundation of the structure with the new supportive structure to protect the structure in the new position.

To implement the repeated requests from female respondents to redesign the structure more comfortable for the users, the design strategies proposed three aspects of flooring, furnishing, and decorating. In the flooring, the surface of the structure proposed repairing with local red stones to create warmer color with harmony with the colors of those traditional bricks in the walls and roof. Those stones also applied for the benching inside with a cover of the strong local jujube woods with brown colors and wonderful patterns. The decoration of the structure limited to remover the plaster from traditional bricks and polish the surface and recovering the wall and roof with a pointing of a light white cement mortar. This pointing with the white color created visual contrast based on the figure and ground theory, so the room could be perceived wider than it was. Artificial light and sockets for power predicated. The process of the design conceptualization summarized in table 3 .

Table 3 Summary of the Key Ideas of the Respondents

\begin{tabular}{|l|l|l|}
\hline Design Strategies & Design Tactics \\
Ponceptualization with & $\begin{array}{l}\text { The box should be open } \\
\text { is some part to be } \\
\text { accessible by users }\end{array}$ \\
\hline $\begin{array}{l}\text { Protection of the structure } \\
\text { in static box }\end{array}$ & $\begin{array}{l}\text { Using of bricks and } \\
\text { concrete to convert the } \\
\text { road weight into the } \\
\text { foundation }\end{array}$ \\
\hline $\begin{array}{l}\text { Monitoring the quality of } \\
\text { the heritage structure }\end{array}$ & $\begin{array}{l}\text { Creation an open ring to } \\
\text { the surrounding of the } \\
\text { structure for periodical } \\
\text { visiting }\end{array}$ \\
\hline $\begin{array}{l}\text { Safety of users to access to } \\
\text { the structure }\end{array}$ & $\begin{array}{l}\text { Shifting the stairs and } \\
\text { entrance from street to } \\
\text { the sidewalk }\end{array}$ \\
\hline
\end{tabular}




\begin{tabular}{|l|l|l|l|}
\hline $\begin{array}{l}\text { Protection of the structure } \\
\text { in agents of heavy lorry }\end{array}$ & $\begin{array}{l}\text { Orientation supported } \\
\text { structure in the } \\
\text { orientation of the road }\end{array}$ \\
\hline $\begin{array}{l}\text { Facilitate inside with small } \\
\text { rehabilitation }\end{array}$ & $\begin{array}{l}\text { flooring and benching } \\
\text { with stone and woods } \\
\text { for resting } \\
\text { and opening the skylight } \\
\text { for ventilation }\end{array}$ \\
\hline
\end{tabular}

\section{Discussion}

Participatory design in a specific case such as historical heritage should limit to the requests and desires on the outcome and output of the action than participation in the design process. Indeed, for creating a consensus among users need to follow the process of decision making similar to Dyson, Hussain, Iversen, and Manzini, the research achieved to great result for the selection of the design approach as conservation-rehabilitation (Dyson, 2004; Hussain, 2010; Hussain, et al., 2012; Iversen \& Dindler, 2014). However, the discussion some professional aspects and detail parts of design could not reach to the expected design solution. Therefore, the results of the research cannot be in the way with the recommendation of Sanders and Stappers about co-design and co-creativities (Sanders \& Stappers, 2008).

Observation, site analysis, precedents analysis has been so effective for the redesigning the historic structure. In detail, observation identified what kind of the material with what quality in the surrounding area existed and these results supported methods of Neuman, Groat, and Silverman (Groat \& Wang, 2002; Neuman, 2006; Silverman, 2004). In addition, visiting some different precedents of historic projects addressed to applicable techniques and material in the design process. Therefore, results supported of the idea Tavasoli, Amicoa also ICHHTO based on the contextual approach to implementing the local material and technology for conservation and rehabilitation (Tavasoli, 2000; Amicoa \& Curràb, 2014; ICHHTO, 2016).

In addition, the documentation of historic elements with as-built maps was significant pre-requisition step for the design process. However, this technique has been common in the archaeology more than in the architecture, but it was an essential technique for a conservation and rehabilitation project. The technique was not only guided the research and design process but also it created a great achievement for the Heritage office for further development or reconstruction. This approach as a technique was mentioned by Groat and Wang, Bell, and Deming in other research projects with different name and process, but the outcome was so effective (Groat \& Wang, 2002; Bell, 2008; Tafahomi, 2010; Deming \& Swaffield, 2011).

The project resulted sufficient consensus between both governmental and governance parts to keep the structure in the same location but with enhancement the quality of the project for local users, tourists, and the heritage office. In this rehabilitation, the legibility structural of the mind of laypeople did not change with regard to comment of Liopis and colleagues based on the role of reference pointing the historic structure (Llopis, et al., 2015). Therefore, the Payab played not only the same role as the reference point in the area but also it could be a highlighted case for visiting both local users and tourists. The conservation of the project did not change the structure or replace the form of the area, so, these results respected to the concern of Radoslav about historic context (Radoslav, et al., 2013).

Application of local materials was the great achievement of the research not only based on the availability and sustainability but also on the cultural background of those materials for the laypeople and users. Indeed, visual and perceptual aspects connected the memory and the reality inside and outside of the historic structure. This approach emphasized the character of the place to support the historical values for inhabitants, city managers, and politicians. This approach obtained to the recommendation of ICHHTO and Heritage implemented, so, the results of the research were analogous with the approach of Brimblecombe to implement the achievement into practice (Heritage, 2005; Brimblecombe \& Grossi, 2014; ICHHTO, 2016).

\section{Conclusion}

Conservation of the historic structure in the position could possibly enhance the environmental sustainability. In detail, the Payab as the historic structure in underground has play the role of the connective element between of the human need and natural resources. This structure not only provided the accessibility of inhabitant to the natural water but also it supported the flora and fauna ecosystem to access the consistent natural water resource. Therefore, a linear form of olds trees on both side of the water stream and bunch of trees at the Payab entrance were manmade elements those applied the natural elements in highlighting of the environmental expressions. This design strategy as the keeping active the historic structure in underground potentially will result to conserve the environment suitability in the area.

In addition, the historic structure had a significance role in the social sustainability between inhabitants particularly for a minority group of old women. In other words, this place was comfortable for the old women to discuss and spending times in a microclimate and with a high level of privacy. This 
specification was unique in the area that it encourages the users to claim the improvement of the physical conditions of the historic structure. Despite the new generation of the virtual social media and other urban facilities, still the historic structure provides the opportunity of such minority group. Thus, this structure provided a place reminding the cultural background, social interaction, and the sense of place.

Furthermore, the historic structure has been part of the built environment and integrated with other architectural elements in the context. Therefore, conservation of the architectural historic element in the area supports the sustainability of the built environment. The historic structure built with the natural, local, and recyclable materials that it fitted with the context. Despite application of concert to stabilize the structure, the rest of the additional elements were provided from the local and natural materials to enhance sustainability of the built environment.

\section{References}

Altman, I. \& Chemers. M. M., (1984). Culture and Environment. California: CUP Archive

American Planning Association, (2006). Planning and Urban Design Standards. New Jersey: John Wiley and Sons Inc.

Amicoa, A. D. \& Curràb, E., (2014). The role of urban built heritage in qualify and quantify resilience, Specific issues in Mediterranean city. Salford Quays. 181 - 189. Elsevier, United Kingdom,

Antoniou, J., (2002). Historic Cairo, a Walk-through Islamic City. Third ed. Cairo, Egypt: the American University in Cairo Press.

Bell, S., (2004). Elements of Visual Design in the Landscape. Second Ed. New York: Spon.

Bell, S., (2008). Design for Outdoor Recreation. Second Ed. Taylor \& Francis: Taylor \& Francis.

Benevolo, L., (1980). The History of the City. MIT Press first edition . The MIT Press.

Brimblecombe, P. \& Grossi, C. M., (2014). Scientific Research into Architectural Conservation. Journal of Architectural Conservation, 12(3): 127-135.

Dandekar, H. C., (1988). Qualitative Method, in Urban Planning, In: Urban Planning. 73-92. Second Edition. McGraw-Hill, New York

Deming, E. M. \& Swaffield, S., (2011). Landscape Architecture Research: Inquiry, Strategy, Design. New Jersey: John Wiley \& Sons, Inc.

Dondis, D. A., (1973). A Primer of Visual Literacy. Cambridge: the MIT Press.

Dyson, R. G., (2004). Strategic Development and SWOT Analysis at the University of Warwick. European Journal of Operational Research, 152(3): 631-640.

Faryling, C., (1993). Research in Art and Design. Royal College of Art Design Papers, 1(1): 1-5.
French, J. S., (1983). Urban Space: A Brief History of the City Square. Dubuque, IA: Kendall/Hunt Publishing Company.

Gehl, J., (2007). Three Types of Outdoor Activities, Outdoor Activities and Quality of Outdoor Spaces. In: M. C. a. S. Tiesdell, ed. Urban Design Reader. 139-142. Oxford: Architectural Press.

Ghirshman, R., (1954). Iran: From the Earliest Times to The Islamic Conquest. Paris: Penguin books.

Groat, L. \& Wang, D., (2002). Architectural Research Methods, New York: John Wiley \& Sons INC.

Harris, C. W. \& Dines, N. T., (1998). Time-Saver Standards for Landscape Architecture: Design and Construction Data. Second Ed. New York: McGraw-Hill Publishing Company.

Heritage, (2005). Discovering the Past, Shaping the Future. Research Strategy 2005-2010. London: English Heritage Center

Hillier, J., (2002). Shadows of Power: An Allegory of Prudence in Land-Use Planning. London: Routledge Press.

Hussain, S., (2010). Empowering Marginalized Children in Developing Countries Through Participatory Design Processes. Co-Design, 6(2): 99117.

Hussain, S., Sanders, E. B. \& Steinert, M., (2012). Participatory Design with Marginalized People in Developing Countries: Challenges and Opportunities Experienced In A Field Study in Cambodia. International Journal of Design. 6: 91e109.

ICHHTO, (2016). Annual Report of Conservation. Tehran, ICHHTO. Iversen, O. S. \& Dindler, C., (2014). Sustaining Participatory Design Initiatives. Co-Design. 10(3-4): 153-170.

Krier, R., (1991). Urban Space. Hong Kong: Academy Editions London.

Laseau, P., (2000). Graphic Thinking for Architects and Designers. Third Ed. New York: Wiley.

Llewelyn-Davies, (2000). Urban Design Compendium. London: English Partnerships.

Llopis, J., Torres, A., Serra, J. \& Garcia, A., (2015). The preservation of the chromatic image of historical cities as a cultural value. The old city of Valencia (Spain). Journal of Cultural Heritage, 16, 1-13. In Press.

Manzini, E. \& Rizzo, F., (2011). Small Projects/Large Changes: Participatory Design as An Open Participated Process. Co-Design, 7(34): $199-215$.

Means, M. C., (2004). Heritage Areas as An Approach to Regional Planning. In: C. Sullivan, ed. Time-Saver Standards for Urban Design. 561-568. McGraw-Hill Companies, New York

Miller, G., Dingwall, R. \& Morphy, E., (2004). Using Qualitative Data and Analysis. In D. Silverman, Qualitative Research: Theory, Method, and Practice. 2nd ed. 325-341. London: Sage Publications.

Morris, A., (1994). History of Urban Form: Before the Industrial Revolutions. Third Edition. New York: Longman.

Moughtin, C., Cuesta, R., Sarris, C. \& Signoretta, P. (1999). Urban Design: Methods and Techniques. Oxford: Architectural Press. 
Neuman, W. L. (2006). Social Research Methods: Qualitative and Quantitative Approaches, London: Fifth Edition. Pearson Education, Ink

Pallasmaa, J., (2005). The Eyes of the Skin: Architecture and the Senses. Reprint 2007 ed. Sussex: John Wiley and Sons Inc.

Radoslav, R., Branea, A. M. \& Găman, M. S., (2013). Rehabilitation Through A Holistic Revitalization Strategy of Historical City Centers Timisoara, Romania. Journal of Cultural Heritage, 14(3): e1-e6.

Raymond, A., (1984). The Great Arab Cities in the 16th-18th Centuries: An Introduction. New York: New York University Press.

Relph, E. (2007). On the identity of places. In: M. C. a. S. Tiesdell, ed. Urban Design Reader. 103-107. Architectural Press. New York

Sanders, E. B.-N. \& Stappers, P. J. (2008). Co-creation and the New Landscapes of Design. Co-Design, 4(1): 5-18.

Shin, H. S., Chen, Y., Lee, W. H. \& Kim, H. D.(2015). Sustainability of Historical Landscape to Gwanghalluwon Garden in Namwon City, Korea. Sustainability. 7: 8565-8586.

Silverman, D. (2004). Qualitative Research: Theory, Method and Practice. New York: SAGE Publications Ltd.

Silverman, D. (2010). Doing Qualitative Research. New York: SAGE
Publisher.

Tabandeh, H. (1969). History of Gonabad. Gonabad: Sepehr.

Tafahomi, R., 2007. Transition Process of Urban Space in Iran. Postgraduate Conference, Faculty of Built Environment, University Technology Malaysia, the Conference Proceeding, 5: 81-88, Johor, Malaysia

Tafahomi, R. (2009). Application the Visual and Graphical Techniques of Urban Design in Urban Vision Documents. Journal of Shar Negar (City Writer). 52: 25-35.

Tafahomi, R. (2010). Documentary of Historical Parts of Gonabad City, Mashhad: Cultural Heritage Organization, Mashhad, Iran.

Tafahomi, R. \& Nadi, R. (2016). Dehistoricisation the Urban Landscape through Transition of the Enclosure Ratio in Urban Fabric of Gonabad City in Iran. J Archit Eng Tech, 5(1): 1-6

Tavasoli, M., (2000). Design in Historical Center of Tehran. Tehran: CAUSR.

Zamani, H., (1994). Gonabad, the Elder of History. Mashhad, Iran: Marandiz. 